\title{
Cloning and sequencing of a [NiFe] hydrogenase operon from Desulfovibrio vulgaris Miyazaki F
}

\author{
Harm M. Deckers, Frankie R. Wilson and Gerrit Voordouw* \\ Division of Biochemistry, Department of Biological Sciences, The University of Calgary, Calgary, Alberta, \\ Canada T2N $1 N 4$
}

(Received 29 March 1990; revised 21 May 1990; accepted 12 June 1990)

\begin{abstract}
A hydrogenase operon was cloned from chromosomal DNA isolated from Desulfovibrio vulgaris Miyazaki F with the use of probes derived from the genes encoding [NiFe] hydrogenase from Desulfovibrio vulgaris Hildenborough. The nucleic acid sequence of the cloned DNA indicates this hydrogenase to be a two-subunit enzyme: the gene for the small subunit $(267$ residues; molecular mass $=28763 \mathrm{Da}$ ) precedes that for the large subunit $(566$ residues; molecular mass = $62495 \mathrm{Da}$ ), as in other [NiFe] and [NiFeSe] hydrogenase operons. The amino acid sequences of the small and large subunits of the Miyazaki hydrogenase share $80 \%$ homology with those of the [NiFe] hydrogenase from Desulfovibrio gigas. Fourteen cysteine residues, ten in the small and four in the large subunit, which are thought to co-ordinate the iron-sulphur clusters and the active-site nickel in [NiFe] hydrogenases, are found to be conserved in the Miyazaki hydrogenase. The subunit molecular masses and amino acid composition derived from the gene sequence are very similar to the data reported for the periplasmic, membrane-bound hydrogenase isolated by Yagi and coworkers, suggesting that this hydrogenase belongs to the general class of [NiFe] hydrogenases, despite its low nickel content and apparently anomalous spectral properties.
\end{abstract}

\section{Introduction}

Two classes of hydrogenases, the iron-only and nickelcontaining hydrogenases have been found in sulphatereducing bacteria. The cloning and sequencing of the structural genes for these hydrogenases has contributed considerably to their characterization and classification. Genes for the [Fe] hydrogenase have been isolated from two species, D. vulgaris Hildenborough and D. vulgaris subsp. oxamicus Monticello (Voordouw et al., 1985, $1989 b$; Voordouw \& Brenner, 1985). [Fe] hydrogenase is a periplasmic two-subunit enzyme (molecular mass $=46 \mathrm{kDa}$ and molecular mass $=10 \mathrm{kDa}$ for the large and small subunits, respectively). The small subunit has a 34 amino acid signal peptide for export of this hydrogenase to the periplasm (Prickril et al., 1986). The [Fe] hydrogenase subunits do not show homology with those of the nickel-containing hydrogenases, which comprise two subclasses, the [NiFe] and [NiFeSe] hydrogenases. The nucleotide sequence of the structural genes of the [NiFe] hydrogenase from D. gigas ( $\mathrm{Li}$ et al.,

The nucleotide sequence data reported in this paper have been submitted to GenBank and have been assigned the accession number M33174.

Abbreviation: nt, nucleotide(s).
1987; Voordouw et al., 1989a) indicates molecular masses of 28 and $61 \mathrm{kDa}$ for the processed small and the large subunit, respectively. The former has a 50 amino acid signal sequence for export of this hydrogenase. $D$. gigas hydrogenase is relatively easily extracted from the Desulfovibrio periplasm (Hatchikian et al., 1978) and shares sequence homology with [ $\mathrm{NiFe}]$ hydrogenases isolated and characterized from bacterial genera other than Desulfovibrio, i.e. Bradyrhizobium japonicum (Sayavedra-Soto et al., 1988), Azotobacter chroococcum (Ford et al., 1990), Rhodobacter capsulatus (Leclerc et al., 1988), Rhodocyclus gelatinosus (Uffen et al., 1990) and Escherichia coli (Menon et al., 1990). The [NiFe] hydrogenases of these latter micro-organisms are generally found to be periplasmic and membrane-bound: they can be isolated only after trypsin and/or detergent treatment of cell membranes. The $\mathrm{COOH}$ terminus of these hydrogenases appears to have an extension of 40-50 amino acid residues, when compared with the $D$. gigas sequence. This extension has a central stretch of 20 hydrophobic amino acids (Menon et al., 1990) and may function in the binding of these enzymes to the membrane.

Hydrogenases containing both selenium and nickel have been isolated from several species of Desulfovibrio and the cloning and sequencing of the genes from 
(a)
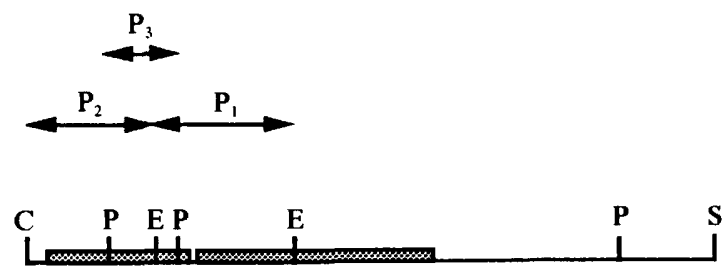

Fig. 1. (a) Restriction map for the $4.8 \mathrm{~kb}$ ClaI-SmaI insert of plasmid DVI (Menon et al., 1990), indicating the coding regions for the small (left) and large (right) subunits ( $)$ of the [NiFe] hydrogenase of D. vulgaris Hildenborough. Restriction sites for $\mathrm{ClaI}$ (C), Pst ( (P), EcoRI (E) and SmaI (S) are indicated, as well as the location of DNA fragments used as probes in the cloning of the Miyazaki hydrogenase genes $\left(P_{1}\right.$, $\mathrm{P}_{2}, \mathrm{P}_{3}$ ). (b) Restriction map of a region of the $D$. vulgaris Miyazaki genome encoding the small and large subunits ( $)$ of Miyazaki hydrogenase. Plasmids pMZSS1-56 and pHCAL2 contained the indicated 3.1 and $3.8 \mathrm{~kb} E c o \mathrm{RI}$ inserts cloned in pUC8. (c) Extent of DNA sequenced by the dideoxychain termination procedure $(6190 \mathrm{nt})$. The sequence displayed in Fig. 3 is indicated ( $)$.

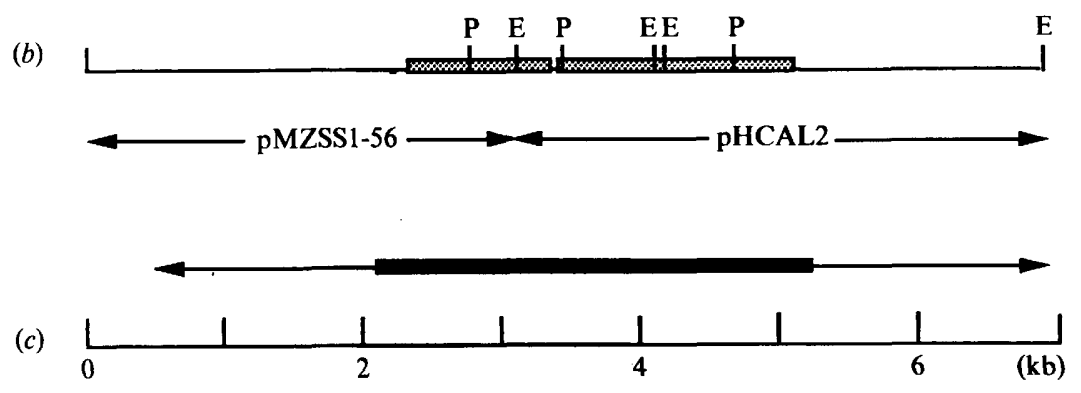

D. baculatus has been reported (Menon et al., 1987; Voordouw et al., 1989a). The sequences of the small (molecular mass $=31 \mathrm{kDa}$ ) and large (molecular mass $=57 \mathrm{kDa}$ ) subunits are homologous to those of the $D$. gigas $[\mathrm{NiFe}]$ hydrogenase, although the degree of sequence identity is less (38 and $34 \%$, respectively, Voordouw et al., 1989a) than that found within the [NiFe] hydrogenase family. The small subunit of [NiFeSe] hydrogenase has a 32 amino acid signal peptide, which shares sequence homology with those for the $[\mathrm{NiFe}]$ and $[\mathrm{Fe}]$ hydrogenase small subunits.

The hydrogenase from $D$. vulgaris Miyazaki $F$ has been extensively studied by Yagi and co-workers (Yagi, 1970; Yagi et al., 1976, 1985; Higuchi et al., 1987). The subunit molecular masses $(29 \mathrm{kDa}$ and $60 \mathrm{kDa})$ and amino acid composition are similar to that of D. gigas hydrogenase (Yagi et al., 1976; Hatchikian et al., 1978). Nevertheless, the nickel content appears to be very low $\left(0.16 \mathrm{~mol} \mathrm{Ni} \mathrm{mol}^{-1}\right)$ and spectroscopic characteristics have been interpreted as an indication of the absence of bound nickel (Yagi et al., 1985). In earlier studies the enzyme was shown to be inhibited by carbon monoxide, a characteristic of [Fe] hydrogenases (Yagi et al., 1976), while lack of inhibition by carbon monoxide is diagnostic for the nickel-containing hydrogenases (Gow et al., 1986; Lissolo et al., 1986). The properties of the Miyazaki $F$ hydrogenase described by Yagi and coworkers are thus unusual and a further investigation of hydrogenases in this strain with molecular biological methods is appropriate. In this study we investigate the possible presence of $[\mathrm{Fe}]$ and $[\mathrm{NiFe}]$ hydrogenase genes in this species with currently available probes and describe the cloning and sequencing of a hydrogenase gene with high homology to the [NiFe] hydrogenase genes of D. gigas.

\section{Methods}

Biochemical reagents. Most of the enzymes used for cloning and sequencing work were obtained from Pharmacia. A sequencing kit containing T7 DNA polymerase ('Sequenase') was obtained from the United States Biochemical Corporation. Radioisotopes deoxyadenosine $5^{\prime}-\alpha-\left[{ }^{35} \mathrm{~S}\right]$ thiotriphosphate $\left[\alpha^{-35}\right] \mathrm{dATP} ;\left(400 \mathrm{Ci} \mathrm{mmol}^{-1}, 14.8\right.$ TBq mmol $\left.{ }^{-1}\right)$ and $\left[\alpha^{-32} \mathrm{P}\right] \mathrm{dATP}\left(3000 \mathrm{Ci} \mathrm{mmol}^{-1}, 111 \mathrm{TBq} \mathrm{mmol}{ }^{-1}\right)$ were purchased from Amersham, and were used for dideoxynucleotide sequencing and nick-translation, respectively. Hybond-N hydribization membranes were also obtained from Amersham.

Bacterial strains, plasmids and DNA isolation. DNA, isolated by the method of Marmur (1961), from D. vulgaris Miyazaki F (IAM 12604, Institute for Applied Microbiology, University of Tokyo, Japan) was kindly donated by Professor T. Yagi, Department of Chemistry, Shizuoka University, Oya, Shizuoka, Japan. DNA from D. vulgaris subsp. vulgaris Hildenborough (NCIB 8303) was similarly isolated in our own laboratory. Vectors pUC8 and M13mp8 or M13mp9 (Vieira \& Messing, 1982; Messing \& Vieira, 1982) were used for gene cloning and dideoxy sequencing, respectively. Plasmid DV1, containing the structural genes of the [NiFe] hydrogenase from $D$. vulgaris Hildenborough on a $4.8 \mathrm{~kb}$ ClaI-SmaI DNA insert in BLUESCRIPT was kindly donated by Dr A. E. Przybyla, Department of Biochemistry, School of Chemical Sciences, University of Georgia, Athens, GA, USA. A restriction map of this insert has been published (Menon et al., 1990) and is presented in Fig. $1(a)$.

pHV150, which contains the hyd $A, B$ genes encoding [ $\mathrm{Fe}$ ] hydrogenase of $D$. vulgaris Hildenborough on a $1.9 \mathrm{~kb}$ Bam HI-BamHI insert has been described elsewhere (Voordouw et al., 1987). A $0.7 \mathrm{~kb}$ hydC probe, containing the $3^{\prime}$ end of the hydC gene (Stokkermans et al., 1989), was isolated from pHVC5 (Voordouw et al., 1989 b). 
Fig. 2. Southern blotting of DNA from $D$. vulgaris Hildenborough and Miyazaki. Blots were incubated with: (a) a $1.9 \mathrm{~kb}$ probe containing the hydA,B genes for $[\mathrm{Fe}]$ hydrogenase from $D$. vulgaris Hildenborough or $(b)$ probe $\mathrm{P}_{1}$ (Fig. 1a). Hildenborough DNA was digested with HindIII (lane 1), EcoRI (lane 2) or Pst I (lane 3). Miyazaki DNA was digested with HindIII (lane 4), EcoRI (lane 5) or Pst I (lane 6). The sizes (kb) of selected fragments derived from the migration of molecular mass markers and the nucleic acid sequence (Fig. 3) are indicated.
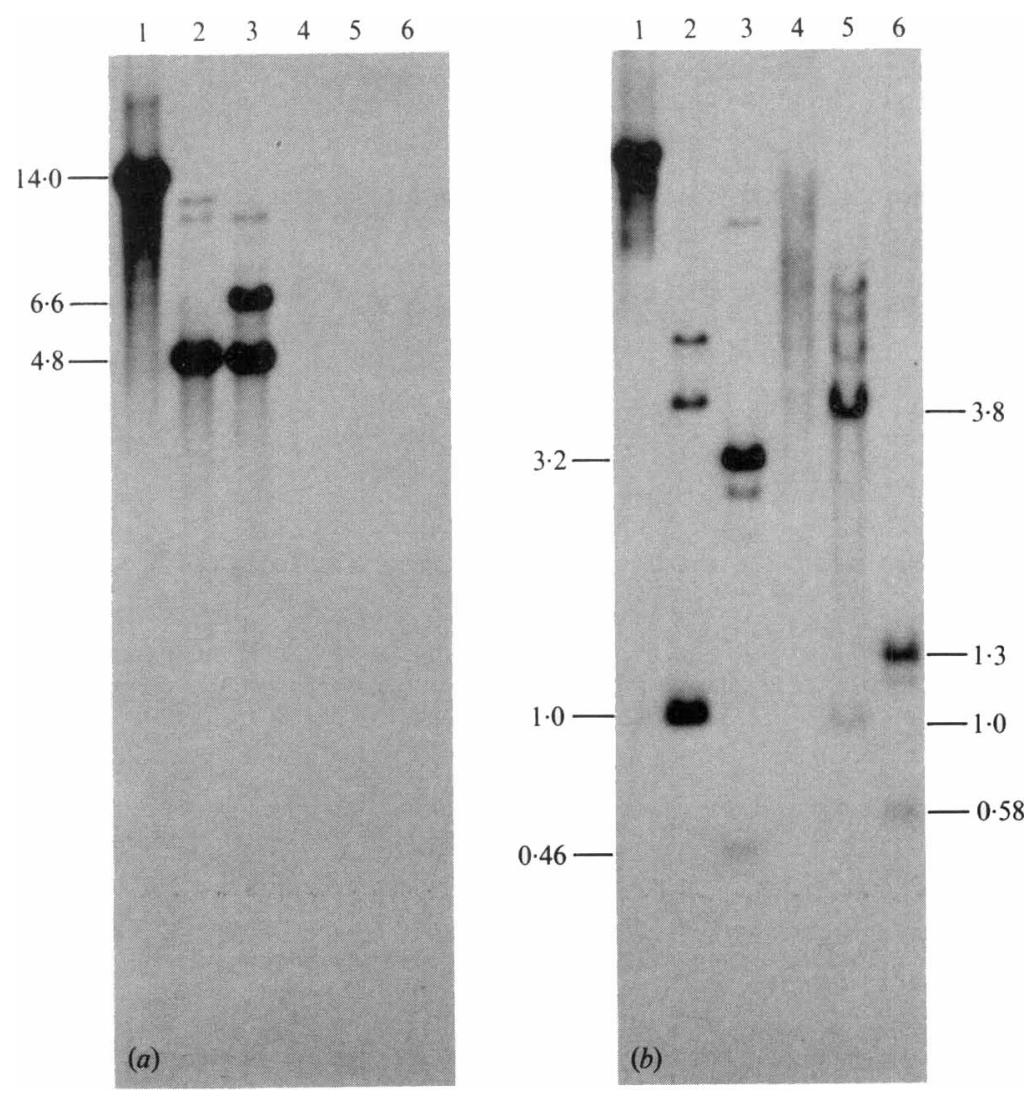

Southern blotting, cloning and dideoxy sequencing. Southern blotting was done with the formamide procedure for Hybond- $\mathrm{N}$ membranes as described previously (Voordouwetal., 1989b). Probes $P_{1}$ and $P_{2}$ (Fig. $1 a$ ) appeared to hybridize with $3.8 \mathrm{~kb}$ and $3.1 \mathrm{~kb} E c o$ RI fragments of $D$. vulgaris Miyazaki DNA, respectively (see Fig. $1 b$ and Results). These hybridizing fragments were cloned in EcoRI-cleaved pUC8 and pHCAL2 and pMZSS1-56, containing the 3.8 and $3.1 \mathrm{~kb}$ EcoRI inserts, were isolated using techniques described previously (Voordouw et al., $1989 b$ ). The inserts of these plasmids were sequenced with the dideoxy chain termination method of Sanger et al. (1977), using the procedures for generating M13 clones with random inserts obtained by sonication as outlined by Bankier \& Barrell (1983). E. coli TG2 (from Toby Gibson, Laboratory of Molecular Biology, Cambridge, UK) was used as the host for these molecular biological manipulations. The sequence data obtained were compiled and analysed in a DEC-VAX computer using the programs of Staden (Staden, 1982, 1984a, $b$; Staden \& McLachlan, 1982) and of the University of Wisconsin Genetics Computer Group (Devereux et al., 1984).

\section{Results}

Using Southern blotting it can readily be shown that $D$. vulgaris Miyazaki $\mathrm{F}$ lacks the hydA,B genes, encoding a periplasmic [Fe] hydrogenase as found in the Hildenborough strain. Digests of chromosomal DNA from the two strains with restriction enzymes HindIII, EcoRI and PstI were electrophoresed through agarose and Southern blotted onto Hybond-N. Following hybridization of the blots with the hydA,B probe the results shown in Fig. 2(a) were obtained. In agreement with earlier data (Voordouw et al., 1985), hybridizing fragments of $14 \mathrm{~kb}$ (HindIII), $4.8 \mathrm{~kb}$ (EcoRI) and 4.8 and $6.6 \mathrm{~kb}$ (Pst I) were observed for Hildenborough DNA (Fig. 2a, lanes 1-3), while Miyazaki DNA was entirely negative (Fig. $2 a$, lanes 4-6). A second gene in D. vulgaris Hildenborough, which could encode a [Fe] hydrogenase, was recently described by Stokkermans et al. (1989). This gene, hydC, is located immediately downstream from the Hildenborough hydA,B genes and has $30-50 \%$ sequence homology with these genes. Hybridization of Miyazaki DNA with a $D$. vulgaris Hildenborough hydC gene probe was tested but was also found to be negative (not shown).

Although D. vulgaris Miyazaki appears to lack genes for [Fe] hydrogenase with homology to those of the Hildenborough strain, its DNA does hybridize with probes derived from the [ $\mathrm{NiFe}]$ hydrogenase genes of $D$. vulgaris Hildenborough. Probe $\mathrm{P}_{\mathbf{1}}$ hybridizes with a $3.8 \mathrm{~kb}$ EcoRI fragment and Pst I fragments of 1.3 and $0.58 \mathrm{~kb}$ (Fig. $2 b$, lanes 5 and 6 ) in agreement with the restriction map for this region of the Miyazaki chromosome, that was established by these experiments and nucleic acid sequencing (Fig. $1 b$ ). One can derive from the distribution of EcoRI sites in Fig. $1(b)$, that the $3.8 \mathrm{~kb}$ 


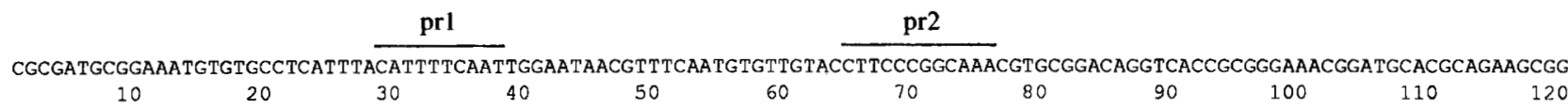
TCGCAGCCGGGGGCCTITCGCACCAGTACGACCCTTACCCCGCCGCGCCGCTGGCGGCGGGCAGGCACGGTGATACGCCGTGCCGAAGGAGGCAGGGATGAAAATCTCGATCGGTCTCG $\begin{array}{llllllllllll}130 & 140 & 150 & 160 & 170 & 180 & 190 & 200 & 210 & 220 & 230 & 240\end{array}$

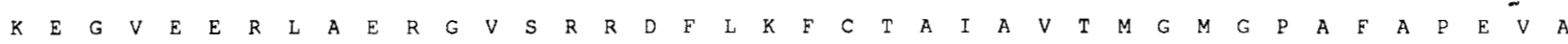
GCAAGGAGGGCGTGGAGGAAAGGCTTGCGGAACGCGGCGTGTCTCGACGCGACTTCCTCAAGTTCTGTACGGCCATCGCCGTGACCATGGGCATGGGCCCCGCGTTCGCGCCGGAAGTTG

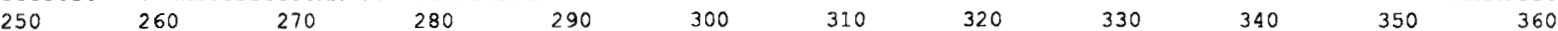

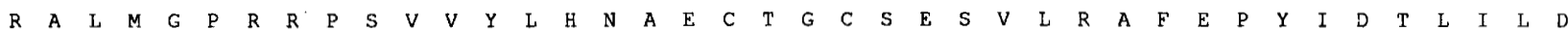
CCCGCGCGCTCATGGGTCCCCGGCGCCCGTCCGTGGTCTACCTGCACAACGCCGAATGCACCGGCTGTTCCGAATCGGTGETGCGCGCGTTCGAACCCTACATCGACACCCTGATTCTGG

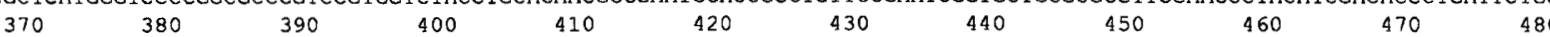

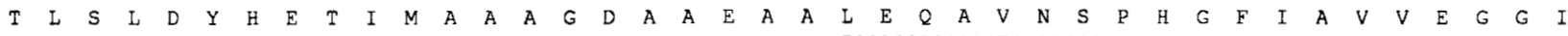
ACACGCTGTCCCTCGACTACCATGAGACCATCATGGCCGCCGCGGGCGATGCGGCGGAAGCCGCCCTGGAGCAGGCCGTCAACAGCCCGCACGGCTTCATCGCCGTGGTGGAAGGCGGCA $\begin{array}{lllllllllll}490 & 500 & 510 & 520 & 530 & 540 & 550 & 560 & 570 & 580 & 590\end{array}$

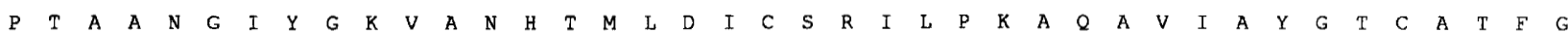
TTCCCACGGCTGCCAACGGCATCTACGGCAAGG TGGCCAACCACACCATGCTGGACATCTGCAGCCGCATCCTGCCCAAGGCCCAGGCCGTCATCGCGTACGGCACCTGCGCCACCTTCG $\begin{array}{lllllllllll}610 & 620 & 630 & 640 & 650 & 660 & 670 & 680 & 690 & 700 & 710\end{array}$

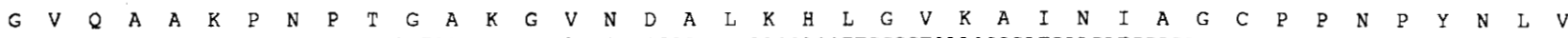
GCGGCGTGCAGGCAGCCAAGCCCAACCCCACCGGTGCCAAGGGCGTCAACGACGCGCTGAAGCACCTTGGCGTCAAGGCCATCAACATCGCCGGTTGCCCGCCGAACCCGTACAACCTGC $\begin{array}{lllllllllll}730 & 740 & 750 & 760 & 770 & 780 & 790 & 800 & 810 & 820 & 830\end{array}$

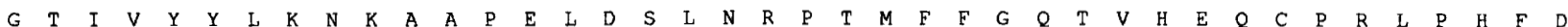
TCGGCACCATCGTGTACTACCTGAAGAACAAGGCCGCGCCCCGAGCTGGACAGCCTGAACCGGCCCACCATGTTCTTCGGCCAGACCGTGCACGAACAGTGCCCCCGCCTACCGCACTTCG

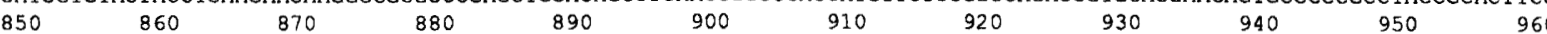

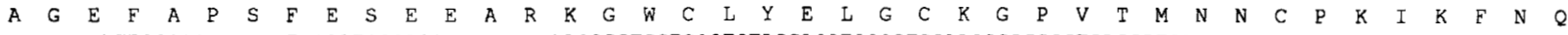
ACGCGGGCGAATTCGCCCCGTCGTTCGAATCGGAAGAAGCCCGCAAGGGCTGGTGCCTCTACGAGCTGGGCTGCAAGGGCCCGGTGACCATGAACAACTGCCCGAAAGATCAAGTTCAACC $\begin{array}{lllllllllll}970 & 980 & 990 & 1000 & 1010 & 1020 & 1030 & 1040 & 1050 & 1060 & 1070\end{array}$

T $N$ N W

AGACCAACTGGCCCGTGGACGCGGGGCACCCCTGCATCGGGTGCAGCGAACCCGATTTCTGGGACGCCATGACCCCGTTCTACCAGAACTGATCACGCGCACGCGCTAGGTCACCCAATA

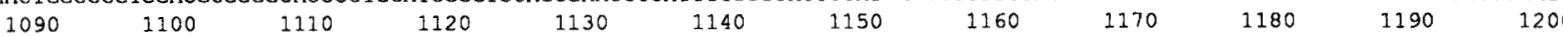
$\begin{array}{rlllllllllllllllllllllllllllllll}\text { rbs } & M & S & G & C & R & A & Q & N & A & P & G & G & I & P & V & T & P & K & S & S & Y & S & G & P & I & V & V & D & P & V\end{array}$

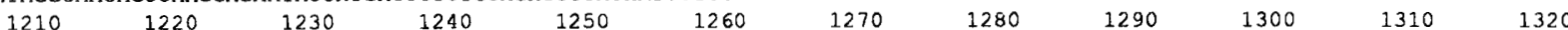

T $R$ R I ACCCGCATCGAAGGCCACCTGCGCATCGAGGTGGAAGTGGAGAACGGCAAGGTCAAGAACGCCTACAGCAGTTCCACGCTGTTCCGGGGCCTTGAAATCATCCTGAAGGGCCGCGACCCC $\begin{array}{llllllllllll}1330 & 1340 & 1350 & 1360 & 1370 & 1380 & 1390 & 1400 & 1410 & 1420 & 1430 & 1440\end{array}$

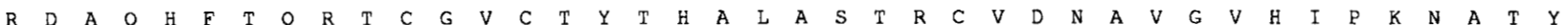
CGCGACGCCCAGCACTTCACCCAGCGCACCTGCGGCGTGTGCACCTATACCCATGCGCTGGCCTCCACCCGCTGCGTGGACAACGCCGTGGGCGTGCACATTCCCAAGAACGCCACCTAC

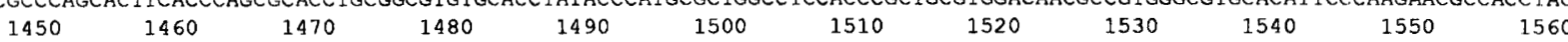

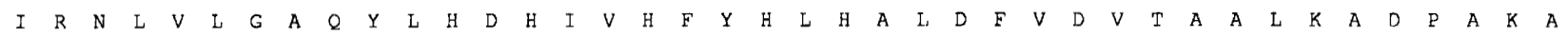
ATCCGCAACCTGGTGCTGGGCGCGCAGTACCTGCACGACCACATCGTGCACTTCTACCACCTGCACGCCCTGGACTTCGTGGACGTGACCGCCGCGCTGAAGGCCGACCCGGCCAAGGCC $\begin{array}{lllllllllll}1570 & 1580 & 1590 & 1600 & 1610 & 1620 & 1630 & 1640 & 1650 & 1660 & 1670\end{array}$

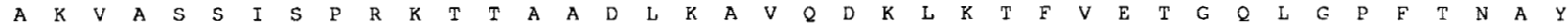
GCCAAGGTGGCCTCGTCCATCTCGCCCCGCAAGACCACGGCGGCGGACCTGAAGGCGGTGCAGGACAAGCTGAAGACCTTCGTGGAAACCGGGCAGCTCGGCCCGTTCACCAATGCCTAC $\begin{array}{llllllllll}1690 & 1700 & 1710 & 1720 & 1730 & 1740 & 1750 & 1760 & 1770 & 1780\end{array}$

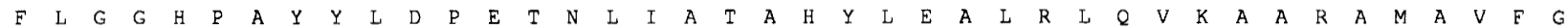
TTCCTGGGCGGCCACCCCGCCTACTACCTGGATCCGGAAACCAACCTCATCGCCACCGCCCACTACCTGGAAGCCCTGCGCCTTCAGGTGAAGGCCGCGCGCGCCATGGCCGTTTTCGGC $\begin{array}{llllllllll}1810 & 1820 & 1830 & 1840 & 1850 & 1860 & 1870 & 1880 & 1890 & 1900\end{array}$

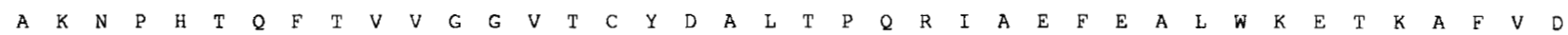
GCCAAGAACCCGCACACCCAGTTCACCGTGGTGGGCGGCGTGACCTGCTACGACGCCCTGACCCCGCAGCGCATCGCCGAATTCGAGGCGCTGTGGAAGGAAACCAAGGCGTTCGTTGAT $\begin{array}{llllllllll}1930 & 1940 & 1950 & 1960 & 1970 & 1980 & 1990 & 2000 & 2010 & 2020\end{array}$

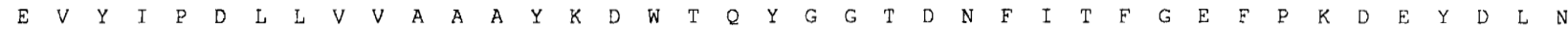
GAAGTGTACATCCCCGACCTGCTGGTGGTTGCCGCGGCCTACAAGGATTGGACGCAGTACGGCGGCACCGACAACTTCATCACCTTCGGCGAATTCCCGAAGGACGAGTACGACCTGAAC $\begin{array}{lllllllll}2050 & 2060 & 2070 & 2080 & 2090 & 2100 & 2110 & 2120 & 2130\end{array}$ 


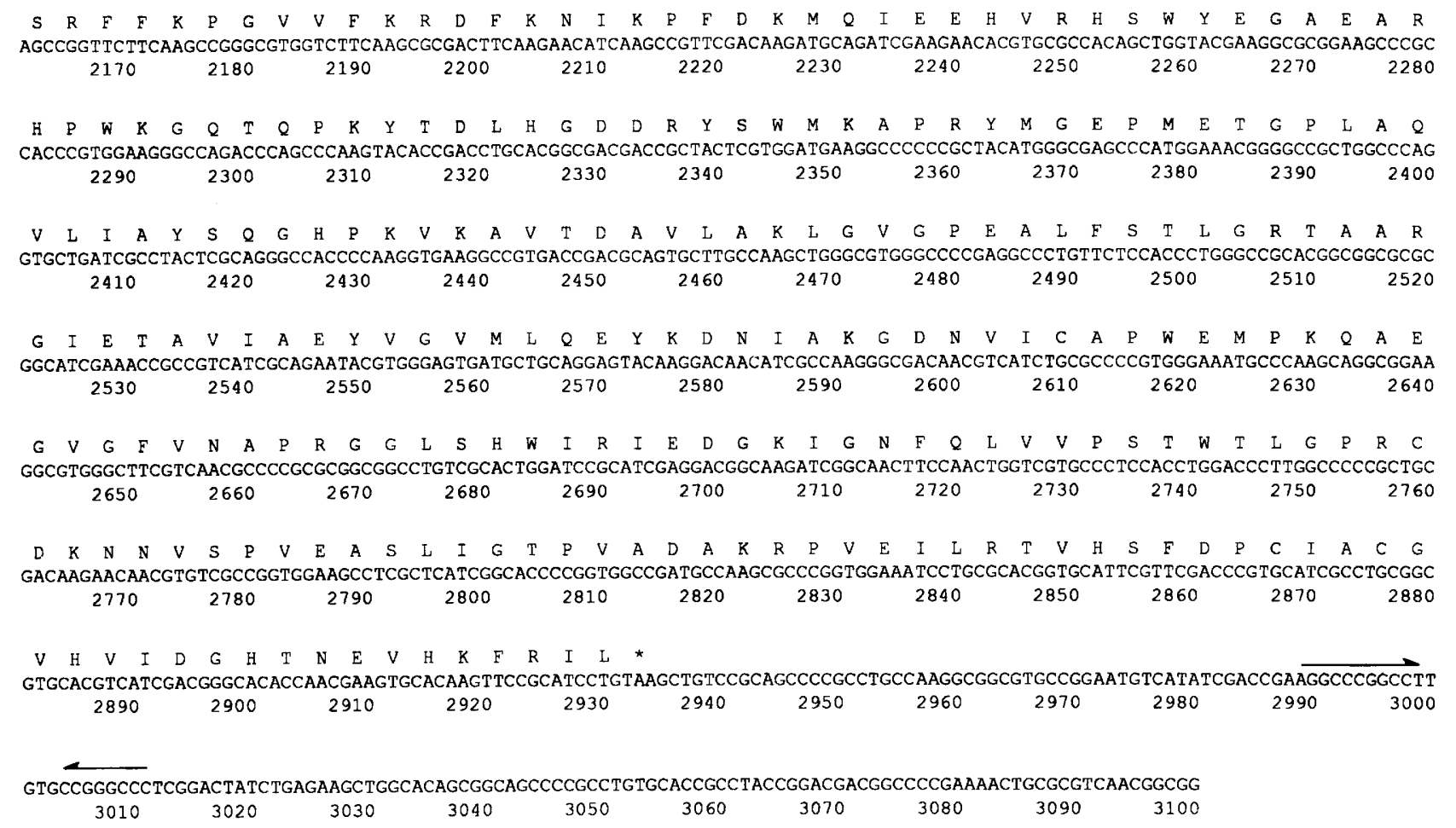

Fig. 3. Nucleotide sequence for the hydrogenase operon from D. vulgaris Miyazaki F. The coding regions for the small (nt 219-1169) and large (nt 1231-2931) subunits have been translated with the one letter amino acid code. Both genes are preceded by a purine-rich ribosome-binding site (rbs). Potential promoter sequences (prl and pr2), discussed in the text, are indicated, as well as a hairpin loop $(\sim)$, that could function in transcription termination.

EcoRI fragment arises from partial digestion: a $1 \mathrm{~kb}$ fragment of Miyazaki DNA is expected to hybridize with $P_{1}$ upon complete digestion. This $1 \mathrm{~kb}$ fragment is present in EcoRI digests of Miyazaki DNA at low intensity (Fig. 2b, lane 5). Complete digestion of the $D$. vulgaris Miyazaki chromosome with EcoRI proved hard to achieve. In contrast complete Pst I digests, showing only hybridization of $P_{1}$ with the 1.3 and $0.58 \mathrm{~kb}$ restriction fragments expected on the basis of the map (Fig. 1b), were achieved consistently, indicating that the more complex EcoRI band pattern is due to partial digestion rather than to the presence of multiple genes.

The $3.8 \mathrm{~kb} E c o$ RI fragment was next cloned by ligating a size-fractionated $E c o$ RI digest $(3-5 \mathrm{~kb})$ of Miyazaki DNA to EcoRI-cut pUC8 and transforming the ligation mixtures into $E$. coli TG2. Recombinant colonies were probed with radiolabelled $P_{1}$ and $a$ positive clone, containing pHCAL2 with the insert as outlined in Fig. 1(b), was isolated. Sequencing of this insert (see below) showed that it contains the entire large subunit gene and part of the $3^{\prime}$ end of the small subunit gene (Fig. $1 b$ ). When Southern blots of EcoRI-digested D. vulgaris Miyazaki DNA were incubated with radiolabelled $\mathrm{P}_{3}$, two hybridizing fragments of 3.8 and $3.1 \mathrm{~kb}$ were observed, while just the $3 \cdot 1 \mathrm{~kb}$ fragment was found to hybridize with probe $\mathrm{P}_{2}$ (not shown). These results indicated that the $3 \cdot 1 \mathrm{~kb}$ fragment contains the $5^{\prime}$ end of the small subunit gene. It was cloned by ligating $2-4 \mathrm{~kb}$ EcoRI fragments and probing the resulting recombinant clones with $\mathrm{P}_{2}$. pMZSS1-56 containing the $3.1 \mathrm{~kb}$ EcoRI insert as indicated in Fig. 1(b) was isolated.

Both the 3.1 and $3.8 \mathrm{~kb} E c o$ RI fragments were sequenced with the shotgun procedure outlined by Bankier \& Barrell (1983). This led to complete determination of the sequence of the $3.8 \mathrm{~kb}$ fragment, while that of the $3.1 \mathrm{~kb}$ fragment was partially determined. Together the two sequences form a contig of 6190 nucleotides (nt), as indicated in Fig. $1(c)$. The sequence of $3100 \mathrm{nt}$ of this contig is shown in Fig. 3, with the proposed reading frames for the small and large subunits of Miyazaki hydrogenase indicated by translation into protein. Every nt of the sequence shown in Fig. 3 was determined at least once on each strand. Several severe compressions could only be read by using T7 DNA polymerase ('Sequenase') rather than Klenow polymerase and by substituting dGTP by dITP in the sequencing reactions.

As indicated in Fig. 3, the gene for the small subunit (nt 219-1169) precedes that for the large subunit (nt 1231-2931) as in other operons encoding [NiFe] or [NiFeSe] hydrogenases (Li et al., 1987; Menon et al., 1987, 1990; Voordouw et al., 1989; Leclerc et al., 1988; 
(a)

1 MKISIGLGKEGVEERLAERGVSRDFLFFTAIAVTMGMGPAFAPEVARA 50

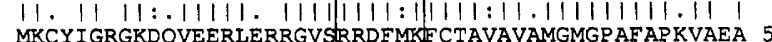
MKCYIGRGKDQVEERLERRGVSRRDFMKFCTAV

51 LMGPRRPSVVYLHNAECTGCSESVLRAFEPYIDTLILDTLSLDYHETIMA 100

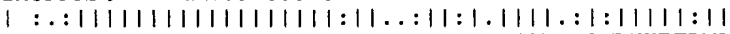
51 LTAKKRP SVVYLHNAECTGCSESLLRTVDPYVDE I ILDVISMDYHETLMA 100

101 AAGDAAEAALEOAVNSP HGF I AVVEGGIPTAANG I YGKVANHTMLD ICSR 150 A 11.11 . 01 GAGHAVEEALHEAIKG DFVCVIEGGIPMGDGGYWGKVGRRNMYDICAE 148 . DFVCVIEGGIPMGDGGYWGKVGRRNMYDICAE

151 ILPKAQAVIAYGTCATFGGVQAAKPNPTGAKGVNDALKHLGVKAINIAGC 200

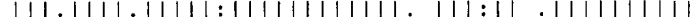

149 VAPKAKAVIAIGTCATYGGVQAAKPNPTGTVGVNEALGKLGVKAIN IAGC 198

201 PPNPYNLVGTIVYYLKNKAAPELDSLNRPTMFFGQTVHEQCPRLPHFDAG 250 $|1| 1|:| 1|:| \ldots 1.1:|1| 1 . .11 .1111: \mid 11: .1111 .11: 11$

199 PPNPMNEVGTVVHLL. TKGMPELDKQGRPVMEFGETVHDNCPRLKHFEAG 247

251 EFAPSFESEEARKGWCLYELGCKGPVTMNNCPKIKFNQTNWPVDAGHPCI 300

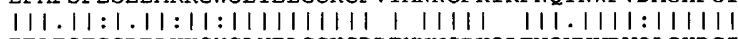

248 EFATSFGSPEAKKGYCLYELGCKGPDTYNNCPKQLFNQVNWPVQAGHPCI 297 $+$ $\uparrow$

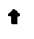

301 GCSEPDFWDAMTPFYQN 317

$:||||:|1|$. $|1|$

298 ACSEPNFWDLYSPFYSA 314

(b)

1 MSGCRAQNAPGGIPVTPKSSYSGP IVVDPVTRIEGHLRIEVEVENGKVKN 50

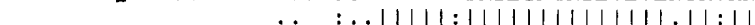
$1 \ldots \ldots \ldots \ldots \ldots$ MSEMQGNKIVVDP ITRIEGHLRIEVEVEGGKIKN 34 $+$

51 AYSSSTLFRGLEIILKGRDPRDAQHFTQRTCGVCTYTHALASTRCVDNAV 100 |:| ||||||||:||||||||||||||||.||||||.|||||.|.|1|. 35 AWSMSTLFRGLEMILKGRDPRDAQHFTQRACGVCTYVHALASVRAVDNCV 84 $\uparrow+$

101 GVHIPKNATYIRNLVLGAOYLHDHIVHFYHLHALDFVDVTAALKADPAKA 150

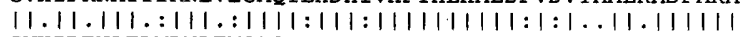
85 GVKIP ENATLMRNLTMGAQYMHDHLVHFYHLHALDWVNVANALNADPAKA 134

151 AKVASSISPRKTTAADLKAVQDKLKTFVETGQLGPFTNAYFLGGHPAYYL 200 $1::|\ldots:||||||\ldots||||| .|:| .:|| .||||||||||||||||||$

135 ARLANDLSPRKTTTESLKAVQAKVKALVESGQLG IFTNAYFLGGHPAYVL 184 201 DPETNLIATAHYLEATRLQVKAARAMAVEGAKNPHTQETVVGGVTCYD : | . : ||||||||||||:||||||||| |||||||||||||||||.| ||.|

185 PAEVDLIATAHYLEALRVQVKAARAMAIFGAKNPHTQFTVVGGCTNYDSL 234

251 TPQRIAEFEALWKETKAFVDEVY IPDLLVVAAAYKDWTQYGGTDNF ITFG 300 $|:||||||:||\ldots:| 1:::|||||| .||:||:.|\ldots|||||:||$

235 RPERIAEFRKL YKEVREF IEOVY ITDLLAVAGF YKNWAG IGKTSNF LTCG 284

301 EFPKDEYDLNSRFFKPGVVFKRDFKNIKPFDKMQIEEHVRHSWYEGAEAR 350

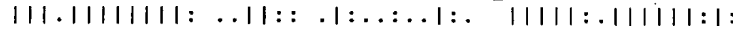

285 EFPTDEYDLNSRYTPQGVIWGNDLSKVDDFNPDL IEEHVKYSWYEGADAH 334

351 HPWKGQTQPKYTDLHGDDRYSWMKAPRYMGEPMETGP LAQVLIAYSQGH . 399

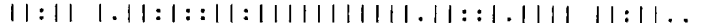

335 HPYKGVTKPKWTEFHGEDRYSWMKAPRYKGEAFEVGPLASVLVAYAKKHE 384

400 PKVKAVTDAVLAKLGVGPEALFSTLGRTAARGIETAVIAEYVGVMLQEYK 449

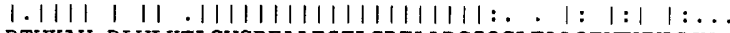

385 PTVKAV.DLVLKTLGVGPEALF STLGRTAARG IQCLTAAQEVEVWLDKLE 433

450 DNIAKGDNVICAPWEMPKOAEGVGFVNAPRGGISHWIRIEDGKIGNFOLV 499

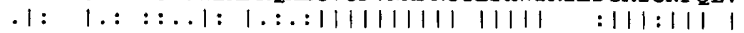
434 ANVKAGKDDLYTDWOYPTESOGVGEVNAPRGMLSHWIVQRGGKIENFQHV 483 $\rightarrow$ 500 VPSTWTLGPRCDKNNVSPVEASL IGTPVADAKRPVE ILRTVHSFDPCIAC 549

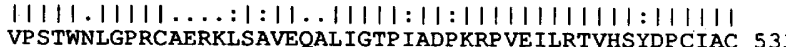
484 VPSTWNLGPRCAERKLSAVEQAL IGTP IADPKRPVE ILRTVHSYDPCIAC

550 GVHVIDGHTNEVHKFRIL 567

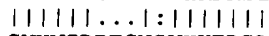

534 GVHVIDPESNQVHKFRIL 551

Fig. 4. Comparison of the amino acid sequences of the small (a) and large (b) subunits of the $D$. vulgaris Miyazaki hydrogenase (top line) with those of the $D$. gigas $[\mathrm{NiFe}]$ hydrogenase (bottom line). The comparison was made with the program GAP of the University of Wisconsin Genetics Computer Group (Devereux et al., 1984). The position of cysteine residues in both subunits is indicated $(\boldsymbol{\uparrow}, \boldsymbol{*})$, as well as the position of a conserved element (boxed) in the small subunit signal sequence.
Sayavedra-Soto et al., 1988; Uffen et al., 1990; Ford et al., 1990). Identical putative ribosome-binding sites (AAGGAG) are located at position -12 to -7 from the initiating ATG codon of both genes, which are separated by an intergenic region of $58 \mathrm{nt}$ (Fig. 3). When the nt sequences upstream from the $D$. vulgaris Miyazaki and D. gigas hydrogenase operons are compared, no homology is observed except for two elements of 10 and $12 \mathrm{nt}$, CATT(T/A)TCAAT and TG(T/G)ACCT(T/G)CCCG. These are, respectively, at position -190 to -181 and -159 to -148 from the translational start of the Miyazaki small subunit gene (Fig. 3) and at position -196 to -187 and -162 to -151 from the translational start of the D. gigas small subunit gene (Voordouw et al., 1989). Although these elements do not resemble the two $E$. coli consensus promoter sequences (TTGACA and TATAAT), they are separated by $21 \mathrm{nt}$, a number similar to the $19 \mathrm{nt}$ found between the two elements in the $E$. coli consensus promoter and are, as indicated above, located in conserved positions relative to the translational start of the small subunit gene in $D$. vulgaris Miyazaki and $D$. gigas. They could therefore be involved in transcription initiation. Since a strong hairpin sequence, which could serve as a transcription terminator, is located immediately downstream from the large subunit gene (nt 2987-3013), it follows that the two structural genes could be transcribed as a single mRNA of approximately $3000 \mathrm{nt}$.

The coding regions for the small (nt 219-1169) and large (nt 1231-2931) subunit of Miyazaki hydrogenase are homologous to those for the small and large subunits of $D$. gigas [NiFe] hydrogenase. A comparison of the amino acid sequences, derived from the sequences of these genes, is shown in Fig. 4 and is discussed below. As expected from the Southern blotting results (Fig. 2a), there is no homology with the $[\mathrm{Fe}]$ hydrogenase genes of D. vulgaris.

\section{Discussion}

The cloning and sequencing of $[\mathrm{NiFe}]$ hydrogenase genes from a variety of bacterial sources has allowed an extensive comparison of homologies in the small and large subunit polypeptide chains, which, in turn, has led to the definition of conserved amino acid, particularly cysteine, residues. Conserved cysteine side-chains are likely to co-ordinate iron-sulphur clusters and the activesite nickel in [NiFe] hydrogenases. There are three ironsulphur clusters in the [NiFe] hydrogenase of $D$. gigas, which has probably been best characterized with spectroscopic methods of all enzymes in this class ( $\mathrm{Li}$ et al., 1987; Moura et al., 1982). Two of these are of the $\mathrm{Fe}_{4} \mathrm{~S}_{4}$ type, requiring four cysteine residues for coordination. The third is a $\mathrm{Fe}_{3} \mathrm{~S}_{4}$ cluster, which is 
presumably co-ordinated by three cysteines (Kissinger $e t$ $a l ., 1989)$. It thus appears that 11 cysteines are required for the co-ordination of iron-sulphur clusters in [NiFe] hydrogenases.

Comparison of primary structures of [ $\mathrm{NiFe}]$ hydrogenase small and large subunits has shown that there are 14 strictly conserved cysteine residues. Perhaps surprisingly, it appears that 10 of these are present in the small, while only four are found in the large subunit. The small subunit appears, therefore, to be the main site for ironsulphur cluster co-ordination in [NiFe] hydrogenases. Using the numbering of the D. gigas sequence in Fig. 4, the 10 strictly conserved cysteines of the small subunit are C-67, C-70, C-162, C-198, C-238, C-263, C-269, C-278, C-296 and C-299, while in the large subunit two groups of two residues are conserved at the $\mathrm{NH}_{2}$ terminus, $\mathrm{C}-65$ and $\mathrm{C}-68$, and at the $\mathrm{COOH}$ terminus, $\mathrm{C}-530$ and $\mathrm{C}-533$. Cysteine residue $\mathrm{C}-530$ serves a special function, since its TGC codon is replaced by a TGA codon, thought to encode selenocysteine, in the [NiFeSe] hydrogenase gene of $D$. baculatus (Voordouw et al., $1989 a$ ). Since it has been shown by spectroscopic studies that this selenocysteine co-ordinates to the nickel (Eidsness et al., 1989) it is now thought that C-530 is also a nickel ligand in [ $\mathrm{NiFe}]$ hydrogenase.

Inspection of Fig. 4 reveals that all 14 cysteine residues listed above have been conserved in the sequence of the Miyazaki hydrogenase. In particular the conservation of C-530 (C-546 in the Miyazaki sequence, Fig. 4b) indicates this hydrogenase to belong to the [NiFe] hydrogenase family.

Apart from cysteine residues the two small subunits show $69 \%$ overall sequence identity and $81 \%$ sequence homology, as calculated with the GAP program (Devereux et al., 1984). Amino acids $1-50$ of the $D$. gigas small subunit (Fig. $4 a$ ) constitute a signal sequence for protein export to the periplasm and the $\mathrm{NH}_{2}$ terminus of the mature small subunit starts with L-51 (Li et al., 1987; Niviere et al., 1988). The sequence of residues $1-50$ of the Miyazaki small subunit is highly conserved. In particular a box of six amino acid residues (RRXFXK), which is present in the small subunit signal sequence of every hydrogenase determined to date (Voordouw et al., 1989 b) is also found in the Miyazaki sequence, while residues 50-51 comprise a signal peptidase processing site identical to that found in the D. gigas small subunit. Residues 1-50 of the Miyazaki small subunit are therefore also expected to function in the export of this hydrogenase to the periplasm. The amino acid sequence of the mature small subunit is 267 residues long and has a calculated molecular mass of $28763 \mathrm{Da}$.

The D. vulgaris Miyazaki and D. gigas large subunits show $68 \%$ sequence identity and $80 \%$ sequence homology (Fig. $4 b$ ). The two sequences are highly homologous at the $\mathrm{COOH}$ terminus and end with the same sequence.
Table 1. Amino acid composition of D. vulgaris Miyazaki hydrogenase as determined from the sequence of the gene

$\left(n_{\mathrm{G}}\right)$ and from the data $\left(n_{\mathrm{Y}}\right)$ of Yagi et al. (1976), recalculated for a total of 833 residues

The $n_{Y}$ value for tryptophan, determined by the method of Bencze \& Schmid (1957), may be inaccurate.

\begin{tabular}{ccc}
\hline \hline Amino acid & $n_{\mathrm{G}}$ & $n_{\mathrm{Y}}$ \\
\hline K & 48 & 45 \\
H & 30 & 25 \\
R & 34 & 27 \\
D N & 77 & 78 \\
T & 52 & 50 \\
S & 31 & 38 \\
E + Q & 70 & 71 \\
P & 56 & 59 \\
G & 67 & 73 \\
A & 89 & 88 \\
C & 20 & 20 \\
V & 67 & 64 \\
M & 13 & 11 \\
I & 43 & 38 \\
L & 58 & 56 \\
Y & 32 & 28 \\
F & 35 & 34 \\
W & 11 & 28 \\
Total & 833 & 833 \\
\hline \hline
\end{tabular}

The Miyazaki large subunit thus also lacks the $\mathrm{COOH}$ terminal extension found in the membrane-bound [ $\mathrm{NiFe}]$ hydrogenases of $E$. coli, B. japonicum and $R$. capsulatus (see Introduction). Apart from an $\mathrm{NH}_{2}$-terminal extension of 16 residues in the Miyazaki large subunit, there are no major differences with the $D$. gigas sequence. The calculated large subunit molecular mass is $62495 \mathrm{Da}$ (566 residues, excluding the initiating methionine).

The Miyazaki hydrogenase genes, that were cloned and sequenced in the present study, are thus highly homologous to those encoding the periplasmic [NiFe] hydrogenase of $D$. gigas. We consider it very likely that these genes encode the periplasmic (Tamura et al., 1988), membrane-bound enzyme purified and characterized by Yagi et al. $(1976,1985)$. The subunit molecular masses derived from the gene sequence are very similar to those determined by Yagi et al. $(1985: 29$ and $60 \mathrm{kDa})$ and the amino acid composition determined for purified hydrogenase (Yagi et al., 1976) is in good agreement with that derived from the sequence of the gene (Table 1). It appears, therefore, that $D$. vulgaris Miyazaki harbours a [NiFe] hydrogenase and there are no obvious features in the amino acid sequence of the enzyme that can explain its unusual enzymic and spectroscopic properties (Yagi et al., 1976, 1985).

This research was supported by an operating grant from the National Science and Engineering Research Council of Canada (NSERC) to G.V. The authors are indebted to Drs T. Yagi and A. E. Przybyla for gifts of chromosomal and plasmid DNA, to Drs P. M. Vignais and A. E. Przybyla for sending preprints of manuscripts and to J. K. Voordouw for technical support. 


\section{References}

BANKIER, A. T. \& BARRELL, B. G. (1983). Shotgun DNA sequencing. In Techniques in the Life Sciences, pp. 1-34. Limerick, Ireland: Elsevier Scientific Publishers Ireland Ltd.

BENCZE, W. L. \& SCHMID, K. (1957). Determination of tyrosine and tryptophan in proteins. Analytical Chemistry 29, 1193-1196.

DevereuX, J., Haeberli, P. \& SMithies, O. (1984). A comprehensive set of sequence analysis programs for the VAX. Nucleic Acids Research 12, 387-395.

Eidsness, M. K., Scott, R. A., Prickril, B., Dervartanian, D. V., LeGall, J., Moura, I., Moura, J. J. G. \& Peck, H. D., JR (1989). Evidence for selenocysteine coordination to the active site nickel in the [NiFeSe] hydrogenase from Desulfovibrio baculatus. Proceedings of the National Academy of Sciences of the United States of America 86, 147-151.

Ford, C. M., Garg, N., Garg, R. P., Tibelius, K. H., Yates, M. G., ARP, D. J. \& SEEFELDT, L. C. (1990). The identification, characterization, sequencing and mutagenesis of the genes (hupSL) encoding the small and large subunits of the $\mathrm{H}_{2}$-uptake hydrogenase of Azotobacter chroococcum. Molecular Microbiology 4 (in the Press).

Gow, L. A., Pankhania, I. P., Ballantine, S. P., Boxer, D. H. \& Hamilton, W. A. (1986). Identification of a membrane-bound hydrogenase of Desulfovibrio vulgaris (Hildenborough). Biochimica et Biophysica Acta 851, 57-64.

Hatchikian, E. C., Bruschi, M. \& LeGall, J. (1978). Characterization of the periplasmic hydrogenase from Desulfovibrio gigas. Biochemical and Biophysical Research Communications 82, 451-461.

Higuchi, Y., Yasuoka, N., Kakudo, M., Katsube, Y., YaGi, T. \& INOKUCHI, H. (1987). Single crystals of hydrogenase from Desulfovibrio vulgaris Miyazaki F. Journal of Biological Chemistry 262, 2823-2825.

Kissinger, C. R., Adman, E. T., Sieker, L. C., Jensen, L. H \& LEGALL, J. (1989). The crystal structure of the three-iron ferredoxin II from D. gigas. FEBS Letters 242, 447-450.

Leclerc, M., Colbeau, A., Cauvin, B. \& Vignais, P. M. (1988). Cloning and sequencing of the genes encoding the large and the small subunits of the $\mathrm{H}_{2}$ uptake hydrogenase (hup) of Rhodobacter capsulatus. Molecular and General Genetics 214, 97-108.

Li, C., Pecx, H. D., JR, LeGall, J. \& Przybyla, A. E. (1987). Cloning, characterization and sequencing of the genes encoding the large and small subunits of the periplasmic [ $\mathrm{NiFe}$ ] hydrogenase of Desulfovibrio gigas. DNA 6, 539-551.

Lissolo, T., Chol, E. S., LeGall, J. \& PeCK, H. D., JR (1986). The presence of multiple intrinsic membrane nickel containing hydrogenase in Desulfovibrio vulgaris (Hildenborough). Biochemical and Biophysical Research Communications 139, 701-708.

MARMUR, J. (1961). A procedure for the isolation of deoxyribonucleic acid from micro-organisms. Journal of Molecular Biology 3, 208-218.

Menon, N. K., PeCK, H. D., JR, LeGall, J. \& Przybyla, A. E. (1987). Cloning and sequencing of the genes encoding the large and small subunits of the periplasmic (NiFeSe) hydrogenase of Desulfovibrio baculatus. Journal of Bacteriology 169, 5401-5407.

Menon, N. K., Robbins, J., Peck, H. D., JR, Chatelus, C. Y., Choi, E.-S. \& PRZYBYLA, A. E. (1990). Cloning and sequencing of a putative Escherichia coli $[\mathrm{NiFe}]$ hydrogenase-1 operon containing six open reading frames. Journal of Bacteriology 172, 1969-1977.

MESSING, J. \& VIEIRA, J. (1982). A new pair of of M13 vectors for selecting either DNA strand of double digest restriction fragments. Gene 19, 269-276.

Moura, J. J. G., Moura, I., Huynh, B.-H., Kruger, H.-J., TeXeira, M., Duvarney, R. C., Dervartanian, D. V., Xavier, A. V., PeCK, H. D. JR \& LEGALL, J. (1982). Unambiguous identification of the nickel EPR signal in ${ }^{61} \mathrm{Ni}$ enriched Desulfovibrio gigas hydrogenase. Biochemical and Biophysical Research Communications 108, 1388-1393.

Niviere, V., Forget, N., Bovier-Lapierre, G., Bonicel, J. \& HATCHIKIAN, C. (1988). Isolation, amino acid analysis and $\mathrm{N}$ - terminal sequence determination of the two subunits of the nickelcontaining hydrogenase of Desulfovibrio gigas. Biochimie 70, 267-271.

Prickril, B. C., CZechowsi, M. H., Przybyla, A. E., Peck, H. D. JR \& LEGALL, J.(1986). Putative signal peptide on the small subunit of the periplasmic hydrogenase from Desulfovibrio vulgaris. Joumal of Bacteriology 167, 722-725.

SANGER, F., Nicklen, S. \& Coulson, A. R. (1977). DNA sequencing with chain-terminating inhibitors. Proceedings of the National Academy of Sciences of the United States of America 74, 5463-5467.

Sayavedra-Soto, L. A., Powell, G. K., Evans, H. J. \& Morris, R. O. (1988). Nucleotide sequence of the genetic loci encoding subunits of Bradyrhizobium japonicum uptake hydrogenase. Proceedings of the National Academy of Sciences of the United States of America 85, 8395-8399.

STADEN, R. (1982). Automation of the computer handling of gel reading data produced by the shotgun method of DNA sequencing. Nucleic Acids Research 10, 4731-4751.

STADEN, R. (1984a). A computer program to determine the function of nucleic acid sequences. Nucleic Acids Research 12, 499-503.

STADEN, R. (1984b). Graphic methods to determine the function of nucleic acid sequences. Nucleic Acids Research 12, 521-538.

StaDEN, R. \& McLACHLAN, A. D. (1982). Codon preference and its use in identifying protein coding regions in long DNA sequences. Nucleic Acids Research 10, 141-156.

Stokkermans. J., van Dongen, W., KaAn, A., van den Berg, W. \& VEEGER, C. (1989). hydy, a gene from Desulfovibrio vulgaris (Hildenborough) encodes a polypeptide homologous to the periplasmic hydrogenase. FEMS Microbiology Letters 58, 217-222.

Tamura, A., KaWATE, T., Ogata, M. \& YAGI, T. (1988). Interaction of cellular hydrogenase, cytochrome $\mathrm{c} 3$ and desulfoviridin in Desulfovibrio vulgaris Miyazaki with their antibodies. Journal of Biochemistry 104, 722-726.

Uffen, R. L., Colbeau, A., Richaud, P. \& Vignais, P. M. (1990). Cloning and sequencing the genes encoding uptake-hydrogenase subunits of Rhodocyclus gelatinosus. Molecular and General Genetics 221, 49-58.

Vieira, J. \& Messing, J. (1982). The pUC plasmids, an M13mp7derived system for insertion mutagenesis and sequencing with synthetic universal primers. Gene 19, 259-268.

VOORDOUW, G. \& BRENNER, S. (1985). Nucleotide sequence of the gene encoding the hydrogenase from Desulfovibrio vulgaris (Hildenborough). European Journal of Biochemistry 148, 515-520.

VOORDOUW, G., WALKER, J. E. \& BRENNER, S. (1985). Cloning of the gene encoding the hydrogenase from Desulfovibrio vulgaris (Hildenborough) and determination of the $\mathrm{NH}_{2}$-terminal sequence. European Journal of Biochemistry 148, 509-514.

Voordouw, G., Hagen, W. R., Kruse-Wolters, M., van BerkelARTS, A. \& VeEger, C. (1987). Purification and characterization of Desulfovibrio vulgaris (Hildenborough) hydrogenase expressed in Escherichia coli. European Journal of Biochemistry 162, 31-36.

Voordouw, G., Menon, N. K., LeGall, J., Choi, E.-S., Peck, H. D. JR \& Przybyla, A. E. (1989a). Analysis and comparison of nucleotide sequences encoding the genes for [NiFe] and [NiFeSe] hydrogenase from Desulfovibrio gigas and Desulfovibrio baculatus. Journal of Bacteriology 171, 2894-2899.

Voordouw, G., Strang, J. D. \& Wilson, F. R. (1989b). Organization of the genes encoding [Fe] hydrogenase in Desulfovibrio vulgaris subsp. oxamicus Monticello. Journal of Bacteriology 171, 38813889.

YAGI, T. (1970). Solubilization, purification and properties of particulate hydrogenase from Desulfovibrio vulgaris. Journal of Biochemistry 68, 649-657.

Yagi, T., Kimura, K., Daidoj, H., Sakai, F., Tamura, S. \& INOKUCHI, H. (1976). Properties of purified hydrogenase from the particulate fraction of Desulfovibrio vulgaris Miyazaki. Journal of Biochemistry 79, 661-671.

YAGI, T., KIMURA, K. \& INOKUCHI, H. (1985). Analysis of the active centre of hydrogenase from Desulfovibrio vulgaris Miyazaki by magnetic measurements. Journal of Biochemistry 97, 181-187. 